Article

\title{
Soil Moisture Estimations Based on Airborne CAROLS L-Band Microwave Data
}

\author{
Mickaël Pardé ${ }^{1}$, Mehrez Zribi ${ }^{2, *}$, Jean-Pierre Wigneron ${ }^{3}$, Monique Dechambre ${ }^{1}$, \\ Pascal Fanise ${ }^{2}$, Yann Kerr ${ }^{2}$, Marc Crapeau ${ }^{3}$, Kauzar Saleh ${ }^{4}$, Jean-Christophe Calvet ${ }^{5}$, \\ Clément Albergel ${ }^{5}$, Arnaud Mialon ${ }^{2}$ and Natalie Novello ${ }^{3}$
}

1 LATMOS, Route de Troux, 78280 Guyancourt, France;

E-Mails: mickael.parde@latmos.ipsl.fr (M.P.); monique.dechambre@latmos.ipsl.fr (M.D.)

2 CESBIO (UPS/CNRS/IRD/CNES), 18 Avenue Edouard Belin, bpi 2801, 31401 Toulouse Cedex 9, France; E-Mails: pascal.fanise@cesbio.cnes.fr (P.F.); yann.kerr@cesbio.cnes.fr (Y.K.); arnaud.mialon@cesbio.cnes.fr (A.M.)

3 INRA, EPHYSE, 71 Avenue Edouard Bourlaux, 33140 Villenave d'Ornon, France; E-Mails: wigneron@bordeaux.inra.fr (J.-P.W.); marc.crapeau@bordeaux.inra.fr (M.C.); nathalie.novello@bordeaux.inra.fr (N.N.)

4 MICINN, CDTI, Cid, 4, 28001 Madrid, Spain; E-Mail: saleh_kauzar@cdti.es

5 CNRM-GAME, Météo-France, CNRS, URA 1357, 42 Avenue Gaspard Coriolis, 31057 Toulouse, France; E-Mails: jean-christophe.calvet@meteo.fr (J.-C.C.); clement.albergel@ecmwf.int (C.A.)

* Author to whom correspondence should be addressed; E-Mail: mehrez.zribi@ird.fr.

Received: 11 October 2011; in revised form: 24 November 2011 / Accepted: 24 November 2011 / Published: 2 December 2011

\begin{abstract}
The SMOS satellite mission, launched in 2009, allows global soil moisture estimations to be made using the L-band Microwave Emission of the Biosphere (L-MEB) model, which simulates the L-band microwave emissions produced by the soil-vegetation layer. This model was calibrated using various sources of in situ and airborne data. In the present study, we propose to evaluate the L-MEB model on the basis of a large set of airborne data, recorded by the CAROLS radiometer during the course of 20 flights made over South West France (the SMOSMANIA site), and supported by simultaneous soil moisture measurements, made in 2009 and 2010. In terms of volumetric soil moisture, the retrieval accuracy achieved with the L-MEB model, with two default roughness parameters, ranges between $8 \%$ and $13 \%$. Local calibrations of the roughness parameter, using data from the 2009 flights for different areas of the site, allowed an accuracy of
\end{abstract}


approximately $5.3 \%$ to be achieved with the 2010 CAROLS data. Simultaneously we estimated the vegetation optical thickness $(\tau)$ and we showed that, when roughness is locally adjusted, MODIS NDVI values are correlated $\left(\mathrm{R}^{2}=0.36\right)$ to $\tau$. Finally, as a consequence of the significant influence of the roughness parameter on the estimated absolute values of soil moisture, we propose to evaluate the relative variability of the soil moisture, using a default soil roughness parameter. The soil moisture variations are estimated with an uncertainty of approximately $6 \%$.

Keywords: soil moisture; CAROLS; L-band; L-MEB; soil roughness

\section{Introduction}

Over recent decades, L-band passive microwave measurements have demonstrated their strong potential for the estimation of soil moisture. Various experimental campaigns have been organized, using towers [1-3] or airborne measurements [4,5], in order to develop inversion algorithms making use of brightness temperature observations. Simultaneously, a radiative transfer model has been proposed to simulate the microwave emission of bare soils and soils with vegetation cover [6]. These were tested and calibrated over agricultural test fields in Europe and the United States.

SMOS, which is the first satellite mission to use L-band passive observations for the retrieval of soil moisture, was launched in November 2009. The L2 processor for soil moisture estimations is based on the L-band Microwave Emission of the Biosphere (L-MEB) model [6,7]. This model has been validated for different types of crops, using in situ and airborne radiometer databases [7,8]. It has been tested on different types of soil conditions, such as wheat fields, grass-covered surfaces, forest areas, frozen conditions [9-12]. Despite various improvements which have been proposed in terms of emissivity modeling, the roughness, which has a strong impact on soil moisture retrieval accuracy [13-15], still remains relatively poorly known: Wigneron et al. [16] considered the roughness parameter, defined by the slope between the rms (root mean square) height and the correlation length. In [11], authors considered the soil roughness to depend on soil moisture. Although these relationships are generally known to vary from one crop to another [8], only a limited number of studies discussed the application and validation of radiometric measurements under heterogeneous conditions prior to the launch of the SMOS mission in 2009.

In the context of the preparation and validation of the SMOS mission, a large number of airborne flights were organized in 2009 and 2010, over the South West of France (SMOSMANIA site), using the CAROLS (Cooperative Airborne Radiometer for Ocean and Land Studies) L-band radiometer. Details of these campaigns are presented in the paper of Zribi et al. [17]. The CAROLS dataset was previously used by Albergel et al. [18], by applying empirical algorithms to estimate soil moisture values, which were then used to validate the SMOS ' $T b$ ' (Brightness temperature) values. These estimations demonstrated that radiometric measurements have a good sensitivity to surface moisture, since the 'RMSE' (Root Mean Square Error) between the estimated and measured 'SM' (Soil Moisture) values was approximately $0.06 \mathrm{~m}^{3} / \mathrm{m}^{3}$, with significant correlations. 
The aim of the present paper is to evaluate the L-MEB model under heterogeneous conditions, with different types of parameterization, using only CAROLS airborne measurements. We tested a two-parameter inversion procedure retrieving both soil moisture and optical thickness simultaneously. In Section 2, we describe the proposed database used in our analysis. In Section 3, we present the L-MEB model, and in Section 4 we analyze the performance of the L-MEB model inversion, when it is applied over the studied site, using CAROLS data. We provide detailed results for three types of application, based on different roughness parameter hypotheses. Our conclusions are presented in Section 5.

\section{CAROLS Database}

\subsection{CAROLS Radiometer}

In 2007, a fully polarimetric radiometer was built, as a copy of the EMIRAD II radiometer, in the context of a collaborative project between the Technical University of Denmark (DTU) and the "Laboratoire Atmosphères, Milieux, Observations Spatiales" (LATMOS) in France.

The CAROLS radiometer has been validated and qualified by means of laboratory measurements and, in particular, has excellent stability and resolution characteristics. The laboratory measurements have shown that this radiometer has a sensitivity of $0.1 \mathrm{~K}$ for an integration time of $1 \mathrm{~s}$, and a relative stability of $0.1 \mathrm{~K}$ over a period of $30 \mathrm{~min}$. Two preliminary campaigns were then carried out in 2007 and 2008. They allowed CAROLS, installed in conjunction with other airborne instruments (STORM radar, GOLD-RTR GPS receiver, an infra-red radiometer, and a visible wide angle camera), to be certified for use in the French ATR-42 research aircraft. The airborne measurements confirmed that the CAROLS data has a good sensitivity, and is in good agreement with the emissivity model over the ocean.

In the aircraft, CAROLS is connected, by means of 4 cables, to two antennas pointed to nadir and to the right side of the aircraft (the slant antenna). The exact location and orientation of the two antennas, inside the aircraft, is determined for each campaign. During each flight, the radiometer switches from one antenna to the other, at a frequency which varies according to the target and the aircraft's altitude. In order to ensure that the radiometer is operated under stable and accurate conditions, various calibration steps were implemented, as briefly described in the following:

- The radiometer is initially calibrated by means of laboratory measurements: we estimated the CAROLS internal noise source temperature "Ndiode" and cable losses, and validated its stability and accuracy.

- During the flights, automatic calibrations were performed by regularly switching the radiometer, between two antennas and an internal source. The proposed calibration [17] is based on a load target (maintained at a temperature Tload) and an additional signal in the form of a noise source (Ndiode).

- The calibration of antenna losses is validated using the ocean as a target. By choosing an area in which the salinity, temperature and wind speed are well known and stable (basically, far from the coast), we are able to accurately estimate the sea surface brightness temperature. 
The quality of the resulting brightness temperature dataset was validated and used in several studies dealing with sea surface salinity [19] as well as soil moisture estimations [18]. In [20], it was also shown that strong Radio Frequency Interference (RFI) had polluted a large number of measurements in both polarizations, made with both antennas. Different methodologies have been proposed to mitigate data corrupted with RFI. In the present study, an optimal mask, based on $T b$ threshold measurements and the statistical Kurtosis parameter, was applied. Moreover, the data was analyzed in detail in order to eliminate measurements corresponding to land with any significant water coverage and urban areas.

Following validation of the CAROLS data recorded in 2007 and 2008, two further campaigns were implemented, with the first of these being made in May 2009, to acquire scientific data for the inversion algorithm, which was then used to provide soil moisture and ocean salinity estimations. The second campaign was spread over a period of three months (April-June 2010), with, as principal objective, the validation of SMOS observations.

\subsection{CAROLS 2009-2010 Flights}

During the first 2009 campaign, 13 flights were conducted during the spring (April and May). They covered three studied sites: the SMOSMANIA site, the VAS site near to Valencia, Spain, and finally the Gulf of Biscay for ocean measurements. For each flight, the French ATR42 research aircraft took off from the Francazal military base in Toulouse. For the four SMOSMANIA flights, various different sites (from Toulouse to the Atlantic Ocean) were overflown, at a generally stable above-ground altitude of 2,000 m. Only over the Nezer forest, towards the western edge of the site, were the measurements carried out at a lower altitude of $600 \mathrm{~m}$. As described in the previous section, the CAROLS measurements provide dual-incidence data, since the radiometer was operated with two antennas, one being pointed to nadir for vertical measurements, and the other being pointed towards the right side of the aircraft (slant antenna), at an incidence angle of approximately $30^{\circ}$.

Figure 1. Illustration of the SMOSMANIA airborne transect, also showing the ground station locations.

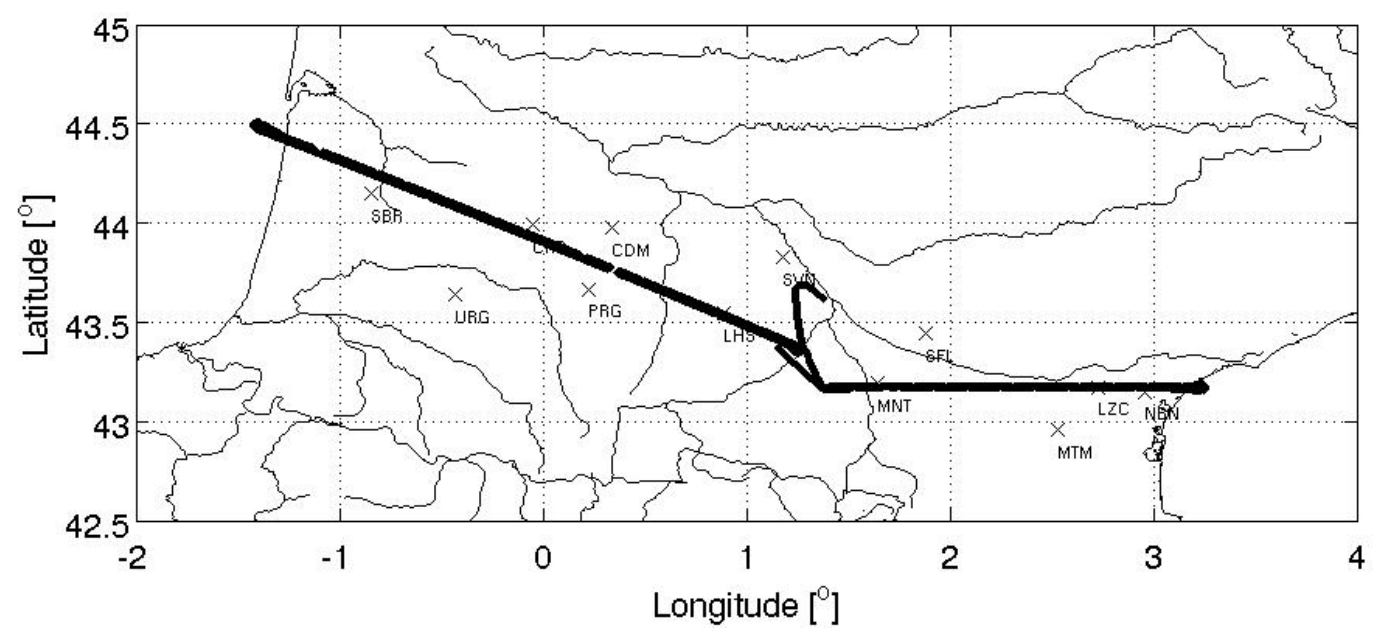

Several months after the launch of SMOS, we began a new campaign, for the purposes of calibrating and validating the SMOS radiometer. Twenty-four flights were made, of which 20 were specifically dedicated to $S M$ monitoring purposes, over the SMOSMANIA site [17]. 
As mentioned in introduction, the analyses of this paper are based only on CAROLS measurements realized over SMOSMANIA site.

Figure 1 illustrates the flight path across South West France, and the location of the SMOSMANIA ground moisture stations. It should be noted that all of the line airborne measurements were made in both directions, in order to determine the brightness temperature of each point at two different incidence angles.

\subsection{Studied Site and Ground Measurements}

During the flights, various automatic and handmade measurements were carried out on the ground: $S M$ and soil temperature (ST) were estimated every $30 \mathrm{~min}$, using respectively ThetaProbe (ThetaProbe ML2X of Delta-T Devices(C) and PT100 sensors installed at the 12 automatic SMOSMANIA stations [21,22]. These measurements were made at four depths $(5,10,20$ and $30 \mathrm{~cm})$. In the present study, we use only the surface measurements at a depth of $5 \mathrm{~cm}$. All the ThetaProbe data were calibrated using gravimetric measurements. It is important to note that the stations were not located directly below the flight path: the most distant station (URG) was $42 \mathrm{~km}$ from the flight line, whereas the closest station was located at a distance of $600 \mathrm{~m}$ from the flight line.

In addition to the SMOSMANIA sites providing continuous measurements, specific test fields were chosen in 2009 and 2010, for the purpose of in situ handmade gravimetric and ThetaProbe SM measurements, simultaneously to CAROLS flights.

As an illustration of the SMOSMANIA soil moisture data, in Figure 2, we plotted the variations in measured surface soil moisture at two stations, situated at the edge of the SMOSmania transect, during 2009 and 2010 campaigns. These two stations are SBR situated in the middle of the "Landes" forest, near the city of Bordeaux, and NBN situated near to the Mediterranean Sea. It can be seen for example that at least 3 important rainfall events occurred during the CAROLS campaign 2010, with varying intensities, depending on the location of each station. For the full set of flights and all stations, we observed $S M$ values ranging between $0.1 \mathrm{~m}^{3} / \mathrm{m}^{3}$ and approximately $0.5 \mathrm{~m}^{3} / \mathrm{m}^{3}$.

Figure 2. Illustration of the temporal evolution of ground soil moisture, and dates of the airborne measurement 2009 and 2010 campaign.

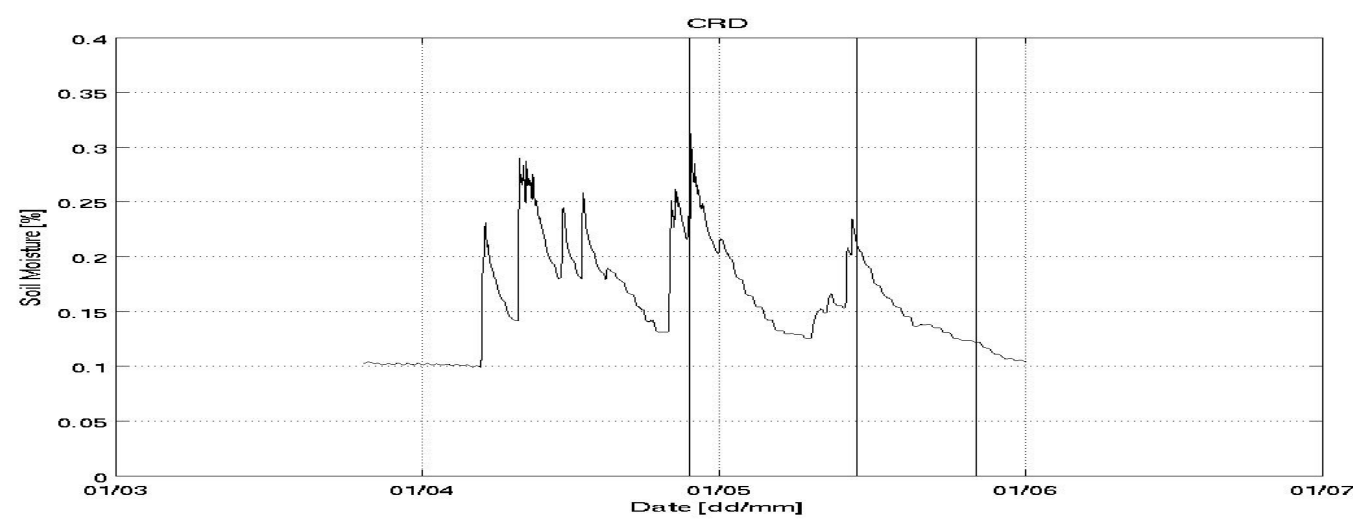


Figure 2. Cont.
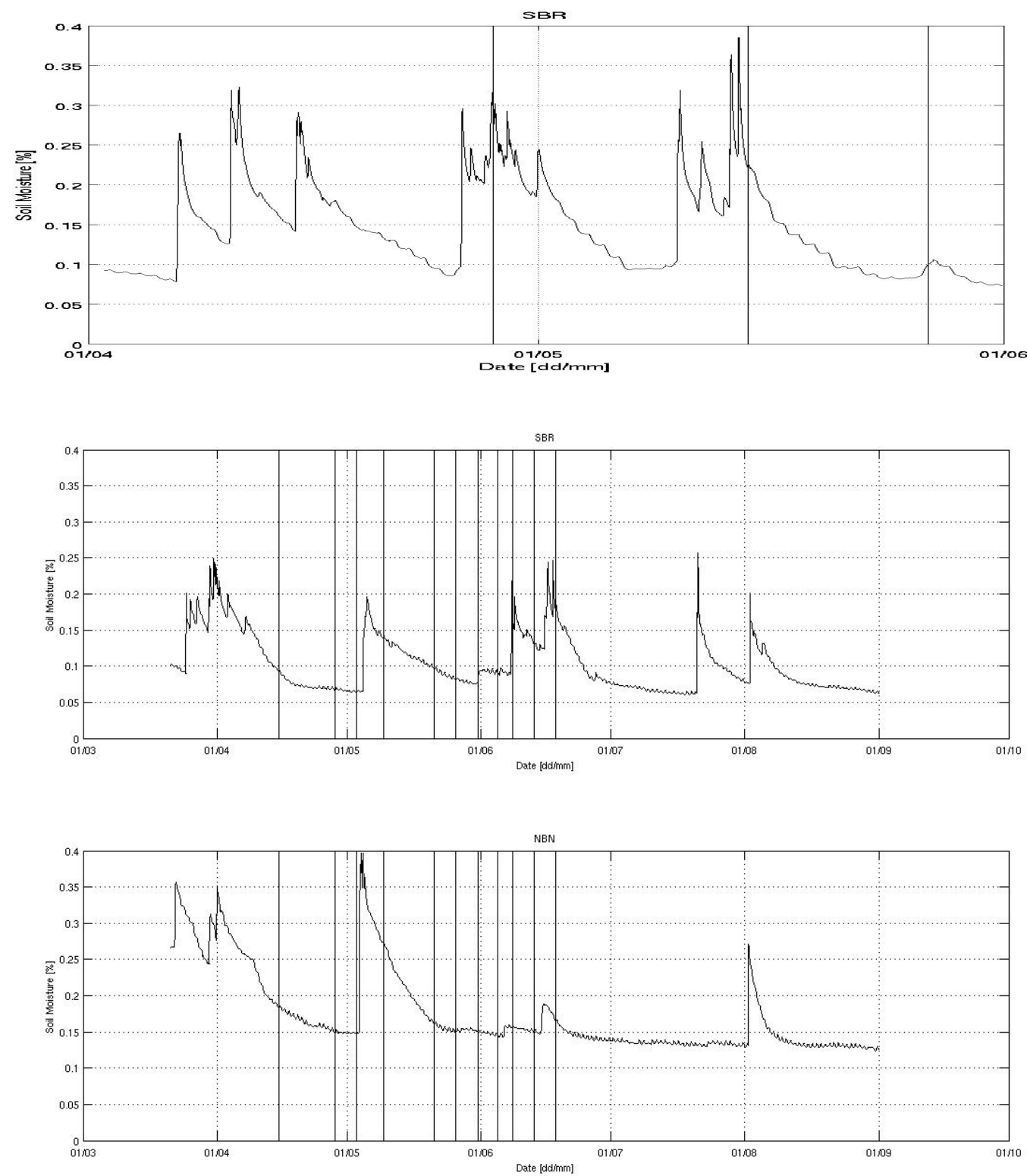

For the purposes of the present study, we first selected 7 stations located close to the flight path: NBN, LZC, MNT, CRD, LHS, SBR, and PRG. However, it was found that the PRG station was located too close to portions of the flights most affected by RFI, and the LZC station was affected by technical problems in 2009 and 2010. These two stations were not considered in our study. We thus consider that reliable measurements were made at the remaining five stations.

\subsection{Auxiliary Data Base}

- Ecoclimap database: In order to estimate $T b$ values along the flight path, it is necessary to compute the soil emissivity, which depends on the soil's structure and dry bulk density. Clay, sand and loam percentages, together with bulk densities, were extracted from the ECOclimap database [23], which provides samples of these parameters at $1 \mathrm{~km}$ intervals. 
- The Normalized Difference Vegetation Index (NDVI) from MODIS: Blue, red, and near-infrared reflectances, centred at $469 \mathrm{~nm}, 645 \mathrm{~nm}$, and $858 \mathrm{~nm}$, respectively, were used to determine the MODIS daily vegetation indices, i.e., the NDVI. We used estimated values, at the 16 day frequency of the AQUA and TERRA satellites, and a resolution of $500 \mathrm{~m}$. Details documenting the MODIS NDVI compositing process and Quality

- Assessment Science Data Sets (QASDS) can be found at NASA's MODIS web site [24].

\section{The L-MEB Model}

\subsection{Direct Radiative Transfer Model}

The model used in the present paper is based on the L-band Microwave Emission of the Biosphere model (L-MEB), described in [7]. It includes the $\tau$ - $\omega$ formulation, which expresses the polarized brightness temperature $\left(T_{b}\right)$ as a function of incidence angle, soil effective temperature, soil emissivity and nadir optical depth $(\tau)$, and the single-scattering albedo $(\omega)$ of the canopy [25].

The soil microwave emissivity is computed using the incidence angle, the Fresnel equations and the dielectric permittivity of the soil computed from the Dobson model [26] as presented in Equation (1). The soil roughness is accounted for using the Wang and Choudhury model [27], based on two parameters, $H_{r}$ and $Q$. The $Q$ parameter value is generally set to zero, and the $H_{r}$ parameter needs to be estimated [5]. The equation describing the soil brightness temperature is the following:

$$
T b_{S, p, \theta}=\left(1-r_{s, p, \theta} \exp \left(-H_{r} \cos (\theta)_{p}^{N}\right)\right) T_{e f f}=\left(1-R_{S, p, \theta}\right) T_{e f f}
$$

where $r_{s, p, \theta}$ is the soil $(S)$ specular reflectivity at $p$ polarization, $R_{S, p, \theta}$ is soil reflectivity equal to $r_{S, p, \theta} \exp \left(-H_{r} \cos (\theta)_{p}^{N}\right), N$ is a power over the cosine factor, usually considered to be 1 and $\theta$ is the incidence angle.

The soil effective temperature $T_{\text {eff }}$ was computed on the basis of the parameterization described in [16], as described in the following Equation (2):

$$
T_{\text {eff }}=T_{\text {depth }}+\left(T_{\text {surf }}-T_{\text {depth }}\right)\left(\frac{S M}{\omega_{0}}\right)^{b_{\omega_{0}}}
$$

where $\omega_{0}$ and $b_{\omega_{0}}$ are two fixed parameters (the default values are $\omega_{0}=0.3 \mathrm{~m}^{3} / \mathrm{m}^{3}$ and $b_{\omega_{0}}=0.3$, [6]). In this equation, the soil temperature of the surface layer $(0-5 \mathrm{~cm})$ should be known $\left(T_{\text {surf }}\right)$, as should the deep soil $(50 \mathrm{~cm})$ temperature $\left(T_{\text {depth }}\right)$. An infrared radiometer is a part of the standard equipment of the research ATR42. It is used to provide surface temperature estimations, simultaneously with the CAROLS measurements. SMOSMANIA continuous measurements provide the deep soil temperature values. The gradient of the temperature effect was assumed to be minimal, and we assumed that the vegetation temperature was equal to that of the surface, as estimated using the infrared temperature.

The complete equation, taking the vegetation effect into account, can be written as follows:

$$
T b_{p, \theta}=\left(\left(1-\omega_{p}\right)\left(1-\gamma_{p, \theta}\right)\left(1+\gamma_{p, \theta} R_{S, p, \theta}+\left(1-R_{S, \theta, p}\right) \gamma_{p, \theta}\right)\right) T_{v}
$$

where $T_{v}$ is the vegetation physical temperature, supposed to be closed to the soil temperature $T_{\text {eff, }}$, and $\gamma$ is the vegetation attenuation factor, which is linked to the optical depth $\tau$ at nadir: 


$$
\gamma_{p, \theta}=\exp \left(\tau_{N A D} / \cos (\theta)\right)
$$

where $\tau_{N A D}$ is the optical depth at nadir.

For the purposes of radiometric modelling, we estimated the clay, sand and loam percentages, as well as the soil density at the surface, using the ECOCLIMAP database [23]. Since an estimation of the deep soil temperature was also needed, we used in situ $\mathrm{T}$ measurements made at the SMOSMANIA sites, at depths of $50 \mathrm{~cm}$.

\subsection{Model Inversion}

In order to estimate the values of the unknown variables, $S M$ and $\tau_{N A D}$ (soil roughness was then supposed to be known under different hypothesis), we used a simple Gauss-Marquardt algorithm, based on nonlinear regression $[10,28]$. This algorithm uses the computation of a modified least squares cost function (Equation (5)), with the possibility of constraining the retrieved parameters:

$$
C_{F}=\frac{\sum\left(T b_{\theta, p}^{M}-T b_{\theta, p}^{E}\right)^{2}}{\sigma_{T b}^{2}}+\frac{\sum\left(p_{i}-p_{i}^{i n i t}\right)}{\sigma_{p_{i}}^{2}}
$$

where $\sigma_{T b}$ is the standard deviation associated with the brightness temperatures, $p_{i}$ is the value of the parameters (retrieved or known), $\sigma_{p_{i}}$ is the standard deviation associated with the parameters and $p_{i}^{i n i t}$ is the initial value of each parameter in the retrieval process. The measured brightness temperatures are $T b^{M}$ and the estimated ones are $T b^{E}$. In the following sections, we always estimate both $S M$ and $\tau_{N A D}$ parameters; we analyze estimated optical thickness variations in the last subsection.

\section{Results and Discussions}

\subsection{Soil Moisture Retrieval with One Roughness L-MEB Default Parameter}

In this section, we consider the case of two default roughness parameter formulations applied to all SMOSMANIA sites. The first of these was proposed by [10], corresponding to a constant value of 0.5 . The second parameter is that proposed in [11], i.e., $H_{r}=1.3-1.13 S M$.

Figure 3 provides a comparison between the estimated volumetric soil moisture values and ground measurements, for each case. Each point corresponds to a measurement taken near to one ThetaProbe ground station of the SMOSMANIA network. For the first roughness value, we compute an rms error of $13 \%$ and a correlation coefficient $\mathrm{R}^{2}$ equal to 0.3 . Similarly, for the second roughness formulation, we find values of $8 \%$ and 0.68 , respectively (Table 2 ). These results illustrate the limitations of this global analysis with the consideration of two fixed roughness formulations, for the determination of accurate soil moisture values.

\subsection{Soil Moisture Retrieval with Local Calibration of the Roughness Parameter}

In this section, we propose to retrieve just one calibrated roughness parameter for each ground station area. We used the data from the 2009 campaigns (airborne data, ground soil moisture 
measurements) to retrieve the $H_{r}$ roughness parameters for each site. Table 3 lists the $H_{r}$ values, retrieved over the different SMOSMANIA station areas. The variations in the roughness parameter can be clearly seen (ranged between 0.7 and 1.7). These values were introduced into the inversion approach, and applied to the data measured during the 2010 flights, in order to retrieve soil moisture. Figure 4 show a comparison between the ground measurements with the retrieved soil moisture estimations. We found an rms error of $5.3 \%$, and a correlation coefficient $\left(\mathrm{R}^{2}\right)$ of 0.92 . This result shows that the accuracy of soil moisture retrieval can be improved, through calibration of the local roughness values.

Figure 3. Inter-comparison between estimated volumetric soil moistures and ground measurements over the SMOSMANIA stations: (a) $H_{r}=0.5$; (b) $H_{r}=1.3-1.13 \mathrm{SM}$.

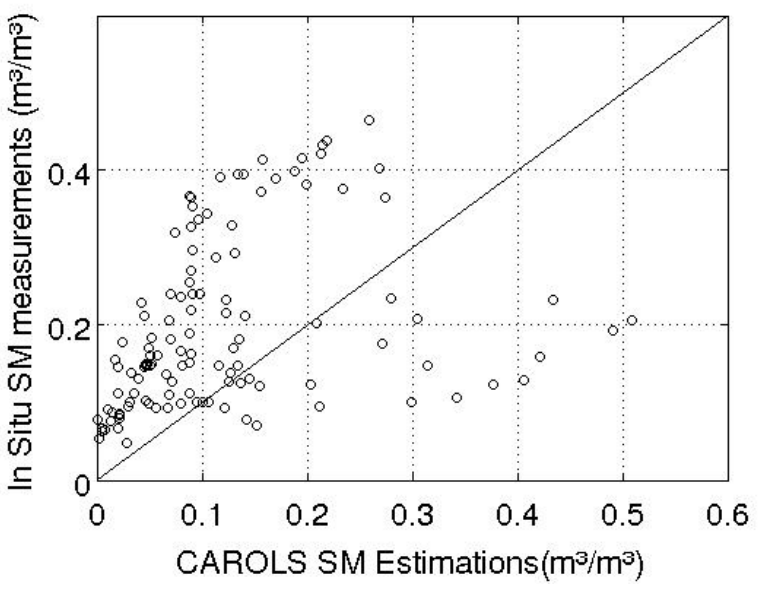

(a)

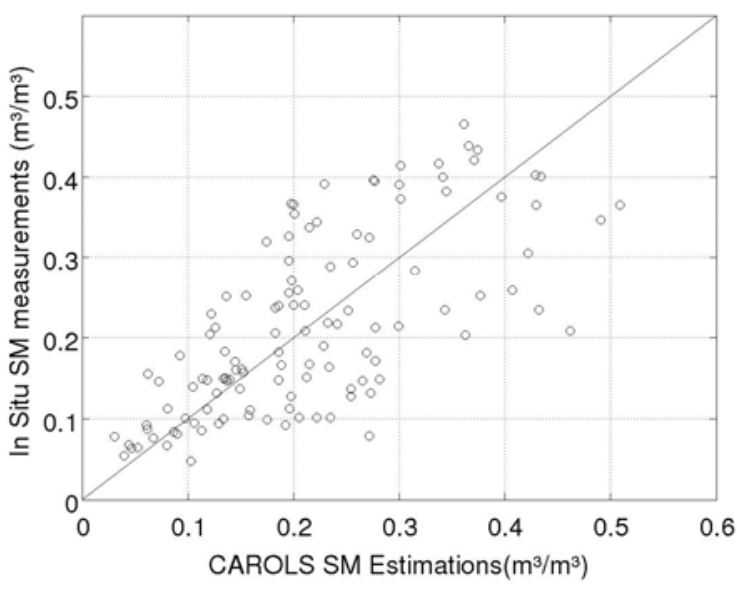

(b)

Table 2. RMSE and $\mathrm{R}^{2}$ values between measured and estimated $S M$ for two default values of $H_{r}$ given by Wigneron et al. [10] and Saleh et al. [11].

\begin{tabular}{cccc}
\hline & RMSE $\left(\mathbf{m}^{\mathbf{3}} / \mathbf{m}^{\mathbf{3}}\right)$ & $\mathbf{R}^{\mathbf{2}}$ & References \\
\hline$H_{r}=0.5$ & 0.133 & 0.3 & {$[10]$} \\
$H_{r}=1.3-1.13 \mathrm{SM}$ & 0.08 & 0.68 & {$[11]$} \\
\hline
\end{tabular}

Table 3. Roughness estimations for different ground stations sites, based on data from the 2009 flights.

\begin{tabular}{cc}
\hline SMOSMANIA Station & $\boldsymbol{H}_{\boldsymbol{r}}$ Values \\
\hline SBR & 1 \\
CRD & 0.7 \\
LHS & 1.7 \\
In situ measurements near to Bordeaux & 1 \\
MNT & 1.7 \\
NBN & 1.3 \\
\hline
\end{tabular}


Figure 4. Inter-comparison between estimated volumetric soil moistures from the 2010 campaigns, following local roughness calibration and ground measurements (black: SBR, red: CRD, magenta: LHS, green: MNT, yellow: NBN, magenta crosses: hand made in situ measurements).

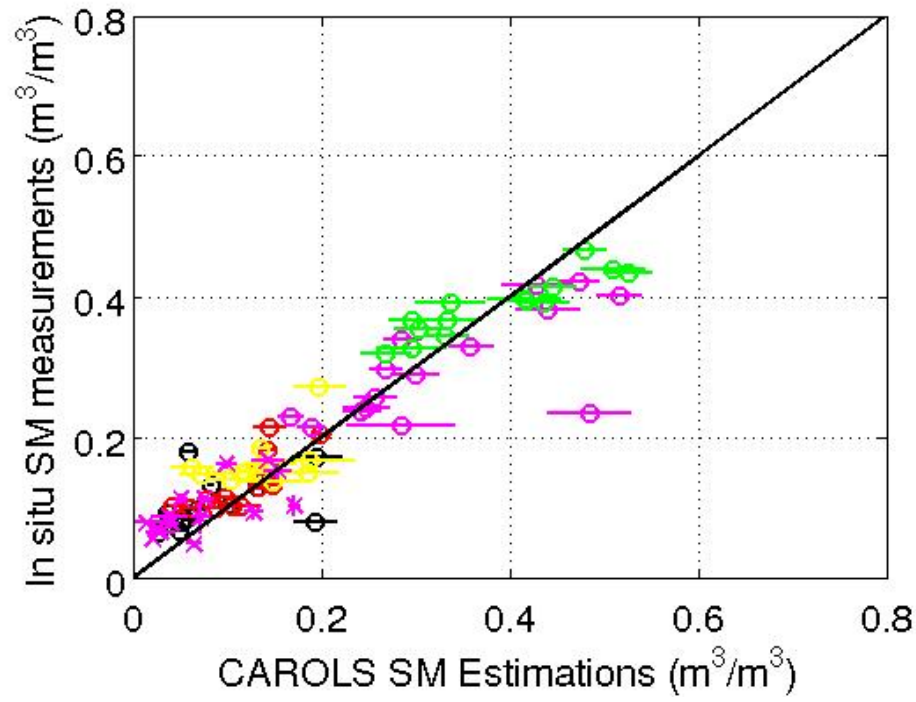

\subsection{Retrieval of Temporal Variations in Soil Moisture}

The two previous sections highlight the importance of local roughness calibrations to ensure that accurate soil moisture estimations are made. In this section, we propose to limit the roughness effect, and to analyze relative soil moisture variations as a function of time only. For these calculations, we consider a fixed roughness parameter relationship $H_{r}=1.3-1.13 \mathrm{SM}$, which remains the same over all the studied areas. We simply compute the $S M$ difference with respect to the values determined on the first date (28 April 2009). In Figure 5 we present the results computed for all flights. We thus determine a relative $r m s$ error of $6 \%$ in the retrieved value of volumetric moisture variations, which is better than that computed for the absolute $S M$ estimations. This good degree of coherence between the remote estimations and the ground measurements suggests that this approach, in which the roughness parameter's influence on the solution is reduced, can be used to improve the overall accuracy of the retrieved soil moisture.

\subsection{Estimation of the Optical Thickness of Vegetation}

Figure 6 provides a scatter plot of the estimated optical thickness, derived from the L-MEB model, with calibrated roughness parameters proposed in Section 4.1 and where $H r$ depends on $S M$ values and the MODIS-NDVI index values over the studied areas. Despite the limited degree of correlation between these two parameters $\left(\mathrm{R}^{2}=0.36\right)$, we observe favorable trends, with a global increase in optical thickness as a function of NDVI. This coherency is confirmed with an increase of tree fraction, extracted from ECOCLIMAP database, for high values of optical thickness. These areas correspond to inversions made over forested areas towards the western edge of the SMOSMANIA site. 
Figure 5. Inter-comparison between estimated temporal variations in volumetric soil moisture and ground measurements (here, a simple global linear relationship was established between $H_{r}$ and $S M$ : $H_{r}=1.3-1.13 S M$ ).

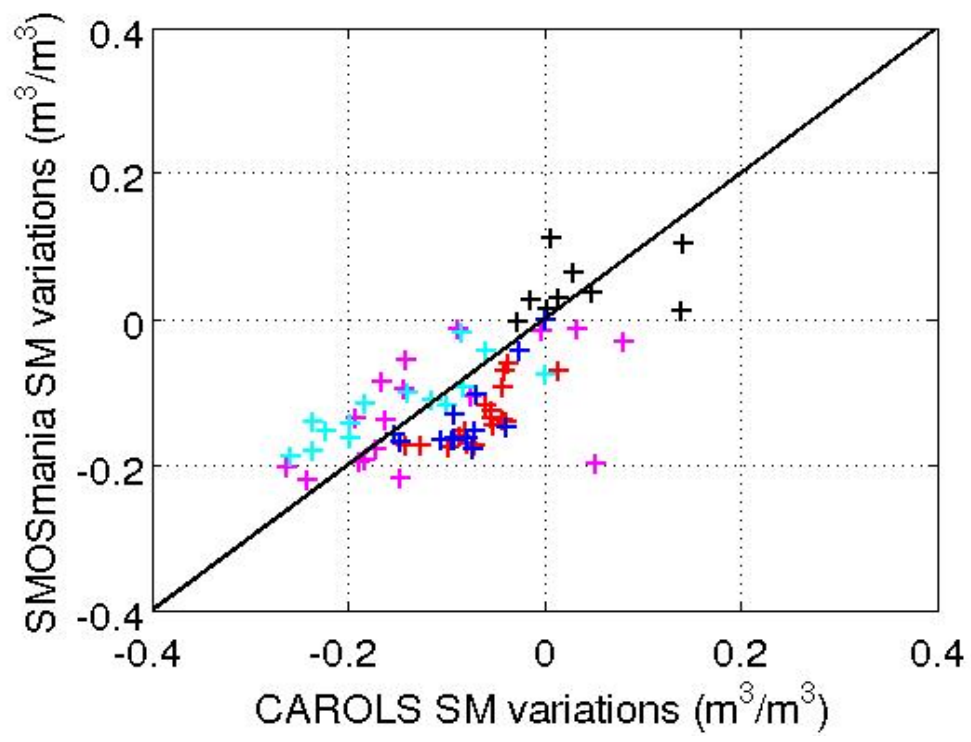

Figure 6. Variations in the retrieved optical thickness and the MODIS NDVI index as a function of the tree percentage over the studied site as recorded in the Ecoclimap database. The red line shows the corresponding linear regression, with $\tau_{N A D}=0.0474 \times \mathrm{NDVI}-0.1702$.

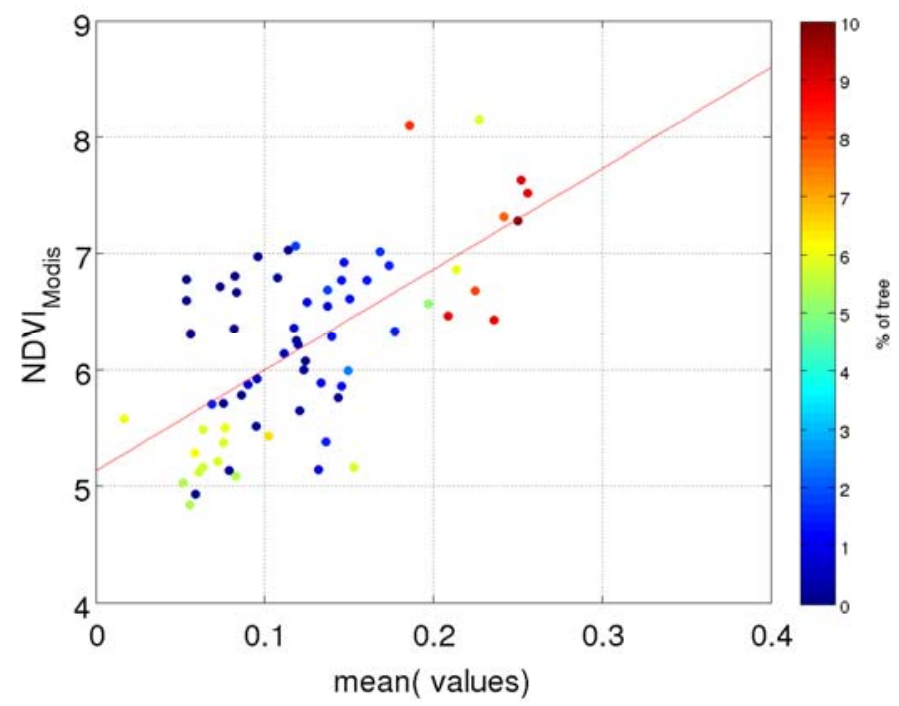

\section{Conclusions}

In this study, we have evaluated the L-MEB model, used for soil moisture retrieval, as proposed for the SMOS level 2 processor. Our study is based on airborne measurements made with the CAROLS radiometer, at an altitude of 2,000 $\mathrm{m}$, which introduce heterogeneity conditions in areas covered by ground measurements. $S M$ is retrieved with an accuracy of $8 \%$, or $13 \%$ when we use a unique parameterization for the roughness to describe all the studied areas: respectively $H_{r}=1.3-1.13 S M$ 
and $H_{r}=0.5$. This outcome demonstrates the limitations of such a hypothesis. When a specific roughness parameter calibration is used for each site, the L-MEB produces results with a greater accuracy, corresponding to an $r m s$ error of $5.3 \%$. In this case, the calibration was carried out using the data from the flights of 2009 (4 flights), while validation was made with 2010 data (20 flights). Simultaneously, this inversion approach showed a high coherency between optical thickness retrievals and NDVI vegetation index estimated using MODIS satellite.

In order to limit the influence of the roughness effect, we propose to analyze the relative temporal variations of $S M$. We consider only one global roughness parameter in our computation. We can estimate the temporal variations in soil moisture for the two campaigns, held in 2009 and 2010, for the same sites with respect to the values determined on the first date. In this case, the estimations are made with a good accuracy, showing an $r m s$ error of $6 \%$. If we consider the $S M$ absolute value as known on the first measurement date (from ground measurement or other satellite sources), we can retrieve absolute $S M$ values for all studied dates. This relative approach could be very useful, particularly for the inversion of SMOS data over specific sites with limited knowledge about roughness.

\section{Acknowledgements}

This work was carried out in the context of a SMOS/ESA Cal/Val project, and was funded by the TOSCA/CNES program. The authors would like to thank the French CNES for the support it gave to the CAROLS project, as well as to all of the CAROLS campaigns. The authors would also like to thank the technical teams from CESBIO, CNRM, LATMOS, LOCEAN, SAFIRE, DT-INSU, DTU, INRA, and the SAFIRE pilots for their support and contributions to the successful airborne and ground campaigns. The MODIS data we used (LAI and NDVI) was made available by the Land Processes Distributed Active Archive Centre (LP DAAC), located at the US Geological Survey (USGS) Earth Resources Observation and Science (EROS) Centre (lpdaac.usgs.gov).

\section{References}

1. Pardé, M.; Wigneron, J.-P.; Chanzy, A.; Kerr, Y.; Calvet, J.-C.; Waldteufel, P.; Søbjærg, S.S.; Skou, N. N-parameter retrievals from L-band microwave measurements over a variety of agricultural crops. IEEE Trans. Geosci. Remote Sens. 2004, 42, 1168-1178.

2. de Rosnay, P.; Calvet, J.C.; Kerr, Y.; Wigneron, J.P.; Lemaitre, F.; Escorihuela, M.J.; Sabater, J.M.; Saleh, K.; Barrie, J.L.; Bouhours, G.; et al. SMOSREX: A long term field campaign experiment for soil moisture and land surface processes remote sensing. Remote Sens. Environ. 2006, 102, 377-389.

3. Grant, J.; Wigneron, J.-P.; Van de Griend, A.A.; Kruszewski, A.; Søbjærg, S.S.; Skou, N. A field experiment on microwave forest radiometry: L-band signal behaviour for varying conditions of surface wetness. Remote Sens. Environ. 2007, 109, 10-19.

4. Jackson, T.J.; Le Vine, D.M.; Griffis, A.J.; Goodrich, D.C.; Schmugge, T.J.; Swift, C.T.; O'Neill, P.E. Soil moisture and rainfall estimation over a semiarid environment with the ESTAR microwave radiometer. IEEE Trans. Geosci. Remote Sens. 1993, 31, 836-841. 
5. Saleh, K.; Kerr, Y.; Richaume, P.; Escorihuela, M.-J.; Panciera, R.; Delwart, S.; Boulet, G.; Maisongrande, P.; Walker, J.P.; Wursteisen, P.; Wigneron, J.-P. Soil moisture retrievals at L-band using a two-step inversion approach (COSMOS/NAFE'05 Experiment). Remote Sens. Environ. 2009, 113, 1304-1312.

6. Wigneron, J.-P.; Kerr, Y.; Waldteufel, P.; Saleh, K.; Escorihuela, M.-J.; Richaume, P.; Ferrazzoli, P.; de Rosnay, P.; Gurney, R.; Calvet, J.-C.; et al. L-band Microwave Emission of the Biosphere (L-MEB) Model: Description and calibration against experimental data sets over crop fields. Remote Sens. Environ. 2007, 107, 639-655.

7. Wigneron, J.-P.; Chanzy, A.; Kerr, Y.; Lawrence, H.; Shi, J.; Escorihuela, M.J.; Mironov, V.; Mialon, A.; Demontoux, F.; de Rosnay, P.; Saleh-Contell, K. Evaluating an improved parameterization of the soil emission in L-MEB. IEEE Trans. Geosci. Remote Sens. 2010, 49, 1177-1189.

8 Panciera, R.; Walker, J.P.; Kalma, J.D.; Kim, E.J.; Saleh, K.; Wigneron, J.-P. Evaluation of the SMOS L-MEB passive microwave soil moisture retrieval algorithm. Remote Sens. Environ. 2009, $113,435-444$.

9. Van de Griend, A.A.; Wigneron, J.P.; Wandteufel, P. Consequences of surface heterogeneity for parameter retrieval from $1.4 \mathrm{GHz}$ multiangle SMOS observations. IEEE Trans. Geosci. Remote Sens. 2003, 41, 803-811.

10. Wigneron, J.-P.; Parde, M.; Waldteufel, P.; Chanzy, A.; Kerr, Y.; Schmidl, S.; Skou, N. Characterizing the dependence of vegetation model parameters on crop structure, incidence angle, and polarization at L-band. IEEE Trans. Geosci. Remote Sens. 2004, 42, 416-425.

11. Saleh, K.; Wigneron, J.-P.; Waldteufel, P.; de Rosnay, P.; Schwank, M.; Calvet, J.-C.; Kerr, Y.H. Estimates of surface soil moisture under grass covers using L-band radiometry. Remote Sens. Environ. 2007, 109, 42-53.

12. Grant, J.P.; Saleh-Contell, K.; Wigneron, J.-P.; Guglielmetti, M.; Kerr, Y.H.; Schwank, M.; Skou, N.; Van de Griend, A.A. Calibration of the L-MEB Model over a coniferous and a deciduous forest. IEEE Trans. Geosci. Remote Sens. 2008, 46, 808-818.

13. Escorihuela, M.-J.; Kerr, Y.; de Rosnay, P.; Wigneron, J.-P.; Calvet, J.-C.; Lemaitre, F. A simple model of the bare soil microwave emission at L-band. IEEE Trans. Geosci. Remote Sens. 2007, 45, 1978-1987.

14. Escorihuela, M.-J.; Chanzy, A.; Wigneron, J.-P.; Kerr, Y. Effective soil moisture depth of L-band radiometry: A case study. Remote Sens. Environ. 2010, 114, 995-1001.

15. Shi, J.C.; Chen, K.S.; Li, Q.; Jackson, T.J.; O’Neill, P.E.; Tsang, L. A parameterized surface reflectivity model and estimation of bare surface soil moisture with L-band radiometer. IEEE Trans. Geosci. Remote Sens. 2002, 40, 2674-2686.

16. Wigneron, J.-P.; Laguerre, L.; Kerr, Y. A simple parameterization of the L-band microwave emission from rough agricultural soils. IEEE Trans. Geosci. Remote Sens. 2001, 39, 1697-1707.

17. Zribi, M.; Pardé, M.; Boutin, J.; Fanise, P.; Hauser, D.; Dechambre, M.; Kerr, Y.; Leduc-Leballeur, M.; Reverdin, G.; Skou, N.; et al. CAROLS: A new airborne L-band radiometer for ocean surface and land observations. Sensors 2011, 11, 719-742. 
18. Albergel, C.; Zakharova, E.; Calvet, J.-C.; Zribi, M.; Pardé, M.; Wigneron, J.-P.; Novello, N.; Kerr, Y.; Mialon, A.; Fritz, N.E.-D. A first assessment of the SMOS data in southwestern France using in situ and airborne soil moisture estimates: The CAROLS airborne campaign. Remote Sens. Environ. 2011, accepted.

19. Martin, A.; Boutin, J.; Hauser, D.; Reverdin, G.; Pardé, M.; Zribi, M.; Fanise, P.; Chanut, J.; Lazure, P.; Tenerelli, J.; Reul, N. Remote Sensing of sea surface salinity from CAROLS L-band radiometer in the Gulf of Biscay. IEEE Trans. Geosci. Remote Sens. 2011, 115, 2718-2728.

20. Pardé, M.; Zribi, M.; Fanise, P.; Dechambre, M. CAROLS L-band radiometer airborn campaign: Analysis of RFI issue. IEEE Trans. Geosci. Remote Sens. 2011, 49, 1063-1070.

21. Albergel, C.; Rüdiger, C.; Pellarin, T.; Calvet, J.-C.; Fritz, N.; Froissard, F.; Suquia, D.; Petitpa, A.; Piguet, B.; Martin, E. From near-surface to root-zone soil moisture using an exponential filter: An assessment of the method based on in situ observations and model simulations. Hydrol. Earth Syst. Sci. 2008, 12, 1323-1337.

22. Calvet, J.-C.; Fritz, N.; Froissard, F.; Suquia, D.; Petitpa, A.; Piguet, B. In situ Soil Moisture Observations for the CAL/VAL of SMOS: The SMOSMANIA Network. In Proceedings of International Geoscience and Remote Sensing Symposium, IGARSS2007, Barcelona, Spain, 23-27 July 2007.

23. Masson, V.; Champeaux, J.L.; Chauvin, F.; Meriguet, C.; Lacaze, R. A global database of land surface parameters at 1-km resolution in meteorological and climate models. J Climate 2003, 16, 1261-1282.

24. MODIS Vegetation Index (MOD 13): Algorithm Theoretical Basis Document; Version 3; 1999. Available online: http://modis.gsfc.nasa.gov/data/atbd/atbd_mod13.pdf (accessed on 14 November 2011).

25. Mo, T.; Choudhury, B.J.; Schmugge, T.J.; Wang, J.R.; Jackson, T.J. A model for microwave emission from vegetation-covered fields. J. Geophys. Res. 1982, 87, 11229-11237.

26. Dobson, M.C.; Ulaby, F.T.; Hallikainen, M.T.; El-Rayes, M.A. Microwave dielectric behavior of wet soil-Part II: Dielectric mixing models. IEEE Trans. Geosci. Remote Sens. 1985, GE-23, $35-46$.

27. Wang, J.R.; Choudhury, B.J. Remote sensing of soil moisture content over bare field at $1.4 \mathrm{GHz}$ frequency. J. Geophys. Res. 1981, 86, 5277-5282.

28. Marquardt, D. An algorithm for least-squares estimation of nonlinear parameters. J. Soc. Ind. Appl. Math. 1963, 11, 431-441.

(C) 2011 by the authors; licensee MDPI, Basel, Switzerland. This article is an open access article distributed under the terms and conditions of the Creative Commons Attribution license (http://creativecommons.org/licenses/by/3.0/). 